\section{Creation of a network for Global Health Students of Norway}

GLOBAL HELSE

\section{GEORGE T. KITCHING}

E-mail: georgki@stud.ntnu.no

George T. Kitching (born 1992), MSc candidate in Public Health specialising in Global Health, at the Department of Public Health and General Practice, Norwegian University of Science and Technology. The author has completed the ICMJE form and reports no conflicts of interest.

\section{ANTON HASSELGREN}

Anton Hasselgren (born 1988), MSc candidate in Public Health specialising in Global Health, at the Department of Public Health and General Practice, Norwegian University of Science and Technology. The author has completed the ICMJE form and reports no conflicts of interest.

\section{CATHRIN BRØNDBO LARSEN}

Cathrin Brøndbo Larsen (born 1989), MSc candidate in Public Health specialising in Global Health, at the Department of Public Health and General Practice, Norwegian University of Science and Technology.

The author has completed the ICMJE form and reports no conflicts of interest.

\section{MARIE SIGSTAD}

Marie Sigstad (born 1990), MSc candidate in Public Health, at the Department of Community Medicine, Arctic University of Norway, Troms $\emptyset$.

The author has completed the ICMJE form and reports no conflicts of interest.

\section{KRISTINA SIVERTSEN}

Kristina Sivertsen (born 1988), MSc candidate in Public Health, at the Department of Community Medicine, Arctic University of Norway, Troms $\emptyset$.

The author has completed the ICMJE form and reports no conflicts of interest.

\section{IRIL NAUSTDAL}

Iril Naustdal (born 1987), MSc candidate in Public Health specialising in Global Health, at the Department of Public Health and General Practice, Norwegian University of Science and Technology. The author has completed the ICMJE form and reports no conflicts of interest.

\section{DAVINA KAUR PATEL}

Davina Kaur Patel MBBS iBSc DTM\&H DFSRH (born 1988), MPhil candidate in International Community Health at the Institute of Health and Society, Faculty of Medicine, University of Oslo. The author has completed the ICMJE form and reports no conflicts of interest.

As students learning and engaging in global health research in Norway, implementing and monitoring the Sustainable Development Goals will affect our work for the next 15 years and 
beyond. In this article we introduce the new network Global Health Students of Norway (GHS-Norway) which aims to forge interdisciplinary connections between students.

Norway has a strong history of global health research, supported by health professionals and scientists. Networks such as the Norwegian Forum for Global Health Research (active for over 10 years) and new initiatives such as the Network for Social Sciences in Norwegian Global Health Research, connect health professionals and scientists to disseminate and discuss current research and new opportunities. Continuing the tradition of strong research begins with students. The health impacts of climate change and implementation and follow-up of the Sustainable Development Goals call for the creation of a closer, interdisciplinary network among students of global health (1-3). We propose to develop a community of students in Norway who are interested in the field of global health, with an emphasis on open channels of communication and cross-collaboration between universities. In short, we propose a network: Global Health Students of Norway (GHSNorway).

This Global Health Students of Norway network will be focused primarily towards masters and doctoral students studying public, international or global health at the Norwegian University of Science and Technology, the University of Bergen, the University of Oslo and the University of Tromsø. As global health issues are complex and transdisciplinary, students from all fields and universities who are eager to learn and engage in global health research are welcome to join.

\section{Proposed network functions}

The critical question this network will address is how to engage and develop a strong interdisciplinary community of students in Norway with knowledge of, and interest in, global health. This network will function as an information hub, by opening communication channels between students interested in global health. This will create possibilities for new research, work opportunities, and potential collaborative projects between universities in Norway and internationally. The network could also help sponsor students to attend global health conferences, arrange digital workshops and link students to existing professional global health networks in Norway and abroad. The Swedish Network for International Health, an inspiring student network developed for Swedish global health students and professionals, is one example of an existing network with similar goals, which has developed successful conferences, a mentorship programme, and an edited student newsletter.

\section{Anticipated benefits}

We anticipate many potential long-term benefits stemming from the creation of Global Health Students of Norway. With enough support and committed student participation, the network could host an annual student-organised conference on global health. Bringing students together is the key to inspiring each other and igniting curiosity. Beyond organising a conference, inter-university partnership could also lead to the establishment of collaborative projects and interdisciplinary teamwork between students, focusing on technological innovation in global health.

Through the creation of links between students interested in global health at these universities, Global Health Students of Norway will help ensure that future generations of health professionals and scientists are well connected and engaged in cross-disciplinary cooperation. We invite all students in Norway interested in global health to join the Global Health Students of Norway. Please contact ghs.norway@gmail.com to join. 
1693-733. [PubMed][CrossRef]

2. Watts N, Adger WN, Agnolucci P et al. Health and climate change: policy responses to protect public health. Lancet 2015; 386:1861 - 914. [PubMed][CrossRef]

3. World Health Organization. Health in 2015: from MDGs, Millennium Development Goals to SDGs, Sustainable Development Goals. 2015

Published: 21 August 2017. Tidsskr Nor Legeforen. DOI: 10.4045/tidsskr.17.0457

Received 21.6.2017, accepted 27.6.2017.

(C) The Journal of the Norwegian Medical Association 2020. Downloaded from tidsskriftet.no 